\title{
Academic Stress and Study Habits of Health Science University Students
}

\author{
Sukesh Shetty ${ }^{1, \odot ~ N e e t h a ~ K a m a t h ~}{ }^{2}$ Nalini M. $^{3}$ \\ ${ }^{1}$ Department of Mental Health Nursing, Nitte Usha Institute of \\ Nursing Sciences, Nitte (deemed to be University), Mangaluru, \\ Karnataka, India \\ ${ }^{2}$ Department of Community Health Nursing, Nitte Usha Institute \\ of Nursing Sciences, Nitte (deemed to be University), Mangaluru, \\ Karnataka, India \\ ${ }^{3}$ Department of Mental Health Nursing, Nitte Usha Institute of \\ Nursing Sciences, Nitte (deemed to be University), Mangaluru, \\ Karnataka, India
}

J Health Allied Sci Nu 2022;12:71-75.

\begin{abstract}
Address for correspondence Sukesh Shetty, MSc, Department of Mental Health Nursing, Nitte Usha Institute of Nursing Sciences, Nitte (Deemed to be University), Mangaluru 575018, Karnataka, India (e-mail: sukeshm@nitte.edu.in).
\end{abstract}

\begin{abstract}
Keywords

- academic stress

- study habits

- undergraduate students

Introduction Academic stress and study habits are crucial indicators of academic success. At the moment, faulty study habits press on the students into academic stress. The present study was conducted to identify the academic stress and study habits of university students of health science.

Methods This cross-sectional descriptive survey was conducted among 150 undergraduate students of nursing, physiotherapy, and pharmacy $(n=50$ in each group). A stratified random sampling technique was used to select the study participants. The information on academic stress and study habits was collected by using the Student Stress Inventory and Palsane and Sharma Study Habit Inventory, respectively. Results Mean score of academic stress was found to be $75.353 \pm 16.463$. Pharmacy students had a higher level of stress compared to physiotherapy and nursing students $(p=0.013)$. Furthermore, the prevalence of unsatisfactory study habits among undergraduate students was $72 \%$, with a mean score of $52.7 \pm 9.152$. Also, nursing students had a higher level of study habits compared to physiotherapy and pharmacy Students. There was no significant relationship found between study habits and academic stress $(r=-0.048, p=0.557)$. There was a significant association found between study habits and gender $(p=0.021)$, as well the association found between stress level and course type, Pre-University Course percentage, and first-year percentage ( $p=0.044,0.04$, and 0.044 respectively).

Conclusion Academic stress and poor study habits are prevalent among undergraduate students. This indicates strategies need to be formed to enhance healthy study habits and alleviate the academic stress of the students, mainly in professional courses; it is an urgent need.
\end{abstract}

\section{Introduction}

Stress may be viewed as an individual's reaction to any change that requires an adjustment or response, which can be

published online

May 29, 2021
DOI https://doi.org/

$10.1055 / \mathrm{s}-0041-1730746$

ISSN 2582-4287 physical, mental, or emotional. Stress and its manifestations such as anxiety, depression, and burnout syndrome are commonly found in professionals. ${ }^{1}$ University curriculum-based academic activities create more stress compared to primary 
education. ${ }^{2}$ The reason may be that in university education, students are going through a transitional phase from adolescence to adulthood. Over these academic years, they try hard to adapt to university life and overcome challenges. In addition to this, they are trying to become financially and emotionally independent (not dependent on their families). ${ }^{3}$

The existing research studies revealed that perceived stress is higher in medical students than nonmedical students. ${ }^{4}$ Previous research also revealed that stress levels are high among nursing, pharmacy, and physiotherapy students. ${ }^{5}$ The cause may be responsibilities placed on these professions. Health care professions have very little tolerance for mistakes. ${ }^{5}$ Other sources which contribute to academic stress are exam-taking, academic workload, grade competition, and a large number of skills to be mastered in a small amount of time. When academic stress is taken negatively, it affects the students' social and psychological well-being. ${ }^{6}$

A study conducted in Norway revealed that undergraduate nursing students have more distress than physiotherapy and occupational therapy students. ${ }^{7}$ Another study conducted in Kathmandu University showed that $74 \%$ of nursing students had high academic stress and 78\% had low self-esteem. ${ }^{8}$ Further, a study conducted in Pakistan by Sabih et al concluded that the prevalence of stress among physiotherapy undergraduate students was $88 \% .{ }^{9}$ Besides, a study conducted at the University of Ghana revealed that 93.6\% of the students indicated that pharmacy education was stressful. ${ }^{6}$

Good study habits are essential for college and university students. The study habits differ in the higher education system in comparison with primary education. The previous research conducted in this area shows that most undergraduate students are unaware of good study habits. They follow the traditional way of study, such as mugging up without understanding practical application. ${ }^{10}$ To support this, a study conducted by Kumar revealed that the majority of the students do not follow effective study habits. This study also shows the majority of the students (48\%) spend less than 10 hours/week on the study and would not revise the topic at home on the day of the lecture (58\%). ${ }^{11}$ Another study conducted by Looyeh et al revealed that undergraduate students study habits are average. ${ }^{12}$ Also, a survey conducted by Dehbozorgi and Mooseli found that $43.4 \%$ of the unsuccessful students had no plans for learning. ${ }^{12}$

Many research studies support that academic stress is widespread among undergraduate health care students, affecting their academic performance and mental health. But there are very few research studies on the study habits of undergraduate health care students. Therefore, the present study aims to find the study habits of undergraduate students and their relation with academic stress, which could be the initial step to plan the measure to relieve academic stress and improve undergraduate students' study habits.

\section{Methods}

A quantitative research approach with a cross-sectional survey design was adopted in the study. The study has followed all ethical guidelines such as obtaining institutional ethics committee (IEC) (reference number: NUINS/CON/NU/IEC/2019-20/1479), taking informed consent from the study participants. A total of 150 study participants were selected by stratified random sampling technique $(n=150)$. For the study, second-year undergraduate nursing, pharmacy and physiotherapy (from each batch, 50 students) students from Nitte (deemed to be university), Mangaluru, were taken. The mean age of the study participants is 19.24 years, in the range between 18 and 23 years. The participants who had medical problems and other health issues were excluded from the study. Participation in the study was purely on a voluntary basis.

\section{Data Collection Tool}

Initially, demographic characteristics such as age, gender, type of family, monthly family income residence, preuniversity exam marks, percentage of first-year marks, and selection of course were collected.

Academic stress of the students was assessed by the Student Stress Inventory (SSI), which was developed by Arip et al to measure the stress among university students. SSI contains 40 negative items to measure 4 subscales (physical, interpersonal relationship, academic factors, and environmental factors). Each subscale had 10 items. It is an ordinal scale and has the option of never, somewhat frequent, frequent, and always. ${ }^{13}$ Score less than 40 is considered as no stress, 40 to 80 considered mild stress, 81 to 121 moderate stress, and 122 to 160 is considered as severe stress. ${ }^{10}$

Students study habits were assessed by Palsane and Sharma Study Habit Inventory (PSSHI) designed by Palsane and Sharma in India (1989). It is a three-option Likert scale consists of 45 items, which assess the study habits of the students in eight areas, including time management (5 items), physical conditions (6 items), learning motivation (6 items), reading ability ( 8 items), note-taking (3 items), memory (4 items), and health of study ( 3 items). Score 2 represents always or mostly, 1 represents sometimes, and 0 represents rarely or never. The score ranges of the questionnaire are between 0 and 90 . Score less than 56 indicates very unsatisfactory study habits, 57 to 58 indicates unsatisfactory, 59 to 64 indicates average, 65 to 67 good, and above 68 is excellent study habits.

The reliability of PSSHI and SSI was assessed by the split-half method. The calculated Pearson-Brown coefficient was 0.8 for both the tools, which indicates that the tools were reliable.

\section{Statistical Analysis}

The statistical analysis was done by using the Statistical Package for the Social Sciences (SPSS-version 20, IBM Corp., Armonk, NY) and Jeffreys's Amazing Statistics Program (JASP Team (2020). JASP (Version 0.14.1)[Computer software]). Descriptive statistics were used to describe the demographic characteristic, study habits, and academic stress. Welch test and analysis of variance (ANOVA) were used to find the difference in the 
study habits and academic stress of university health science undergraduate students. The relationship between academic stress and study habits were found by using the Spearman correlation coefficient. Association between academic stress and study habits with demographic variables were assessed by chisquare test and likelihood ratio. For the present study, $p$-value less than 0.05 is considered as significant.

\section{Results}

\section{Demographic Characteristics}

- Table 1 represents the demographic characteristics of the study participants. Out of 150 study participants, most (74\%) were women and their age group ranged between 18 and 19 years. Most of them were staying in hostels (70\%) and belonged to nuclear families (88\%). Also, majority of them had joined the course by their own interest (79.3\%).

Table 1 Demographic characteristics of undergraduate students

\begin{tabular}{|c|c|c|c|}
\hline \multicolumn{2}{|c|}{$\begin{array}{l}\text { Demographic characteristic ( } n \\
=150 \text { ) }\end{array}$} & $\begin{array}{l}\text { Frequency } \\
\text { (f) }\end{array}$ & $\begin{array}{l}\text { Percentage } \\
\text { (\%) }\end{array}$ \\
\hline \multirow[t]{3}{*}{ Age in years } & $18-19$ & 107 & 71.3 \\
\hline & $20-21$ & 41 & 27.33 \\
\hline & $22-23$ & 2 & 1.3 \\
\hline \multirow[t]{2}{*}{ Gender } & Male & 39 & 26 \\
\hline & Female & 111 & 74 \\
\hline \multirow{3}{*}{$\begin{array}{l}\text { Types of } \\
\text { family }\end{array}$} & Nuclear & 133 & 88.6 \\
\hline & Joint & 15 & 10 \\
\hline & Extended & 4 & 2.6 \\
\hline \multirow{4}{*}{$\begin{array}{l}\text { Monthly } \\
\text { family } \\
\text { income (Rs) }\end{array}$} & $>100,000$ & 11 & 7.3 \\
\hline & $50,000-100,000$ & 27 & 18 \\
\hline & $30,000-50,000$ & 57 & 38 \\
\hline & $<20,000$ & 55 & 36.6 \\
\hline \multirow[t]{4}{*}{ Residence } & Hostel & 105 & 70 \\
\hline & Home & 39 & 26 \\
\hline & Paying guest & 2 & 1.3 \\
\hline & Rent & 4 & 2.6 \\
\hline \multirow{5}{*}{$\begin{array}{l}\text { Preuniversity } \\
\text { college } \\
\text { percentage }\end{array}$} & $>95 \%$ & 6 & 4 \\
\hline & $85-94.9 \%$ & 26 & 17.3 \\
\hline & $75-84.9 \%$ & 54 & 36 \\
\hline & $70-74.9 \%$ & 45 & 30 \\
\hline & $<70 \%$ & 19 & 12.6 \\
\hline \multirow{5}{*}{$\begin{array}{l}\text { First-year } \\
\text { marks in } \\
\text { percentage }\end{array}$} & $>90 \%$ & 4 & 2.6 \\
\hline & $80-89.9 \%$ & 29 & 19.3 \\
\hline & $70-79.9 \%$ & 32 & 21.3 \\
\hline & $60-69.9 \%$ & 74 & 49.3 \\
\hline & $<50 \%$ & 11 & 7.3 \\
\hline \multirow{4}{*}{$\begin{array}{l}\text { Selection of } \\
\text { course }\end{array}$} & By self & 119 & 79.3 \\
\hline & Parent's force & 12 & 8 \\
\hline & Relative's force & 5 & 3.3 \\
\hline & Any other & 14 & 9.3 \\
\hline
\end{tabular}

\section{Study Habits of Undergraduate Students}

-Fig. 1 depicts the level of study habits among 150 undergraduate students. It shows the majority (62\%) had very unsatisfactory study habits, $10 \%$ had unsatisfactory study habits, $19.3 \%$ had an average study habit, $5.3 \%$ had good, and only $3.3 \%$ had excellent study habits. The mean study habits score of undergraduate students were $52.7 \pm 9.152$

In - Table 2, the Welch test shows the significant difference in the study habits of nursing, pharmacy, and physiotherapy undergraduate students, that is, $\mathrm{H}^{2}=7.081, p=0.029$ (-Table 2). Further, the post hoc test using Games-Howell correction showed that the nursing students had a higher level of study habits than physiotherapy students (mean difference $=5.280, p=0.008$ ). There was no significant difference found between study habits of nursing and pharmacy ( $p=0.366)$, and pharmacy and physiotherapy undergraduate students $(p=0.282)$.

\section{Academic Stress of Undergraduate Students}

- Table 3 shows that among 150 students, the majority (64\%) had mild academic stress, and $36 \%$ had a moderate level of stress. However, no students were there in the category of no stress and severe level of stress. The mean stress score of undergraduate students is $75.353 \pm 16.463$.

Comparison of Academic Stress in Nursing, Pharmacy, and Physiotherapy Undergraduate Students

As shown in Table 4, the independent one-way ANOVA showed a significant difference between stress score of nursing, pharmacy, and physiotherapy students, that is, $F(2,147)=4.477, p=0.013$ (4). Further, the post hoc test using Tukey's correction revealed that physiotherapy students had a higher level of stress than pharmacy students (mean difference $=9.260, p=0.013$ ) . In contrast, there was no significant difference found in the stress level between pharmacy and nursing $(p=0.083)$, and nursing and physiotherapy $(p=0.74)$ students.

\section{Correlation between Academic Stress and Study Habits}

- Table 5 shows a weak negative correlation between academic stress and study habits $(r=-0.048)$. However, it was not statistically significant $(p=0.557)$.

\section{Association between Academic Stress and Study Habits with Demographical Variables}

The likelihood ratio was computed and it was found that there was no significant association between study habits and demographic variables except for gender $(p=0.021)$. Furthermore, there was a significant association found between stress level and demographic variables such as course type, PUC percentage, and first-year percentage ( $p$-value $0.044,0.04$, and 0.044 , respectively).

\section{Discussion}

Present study findings are consistent with the study conducted by Mendezabal, which revealed that 239 Filipino students' study habits were also ineffective and insufficient. ${ }^{14}$ Also, a 


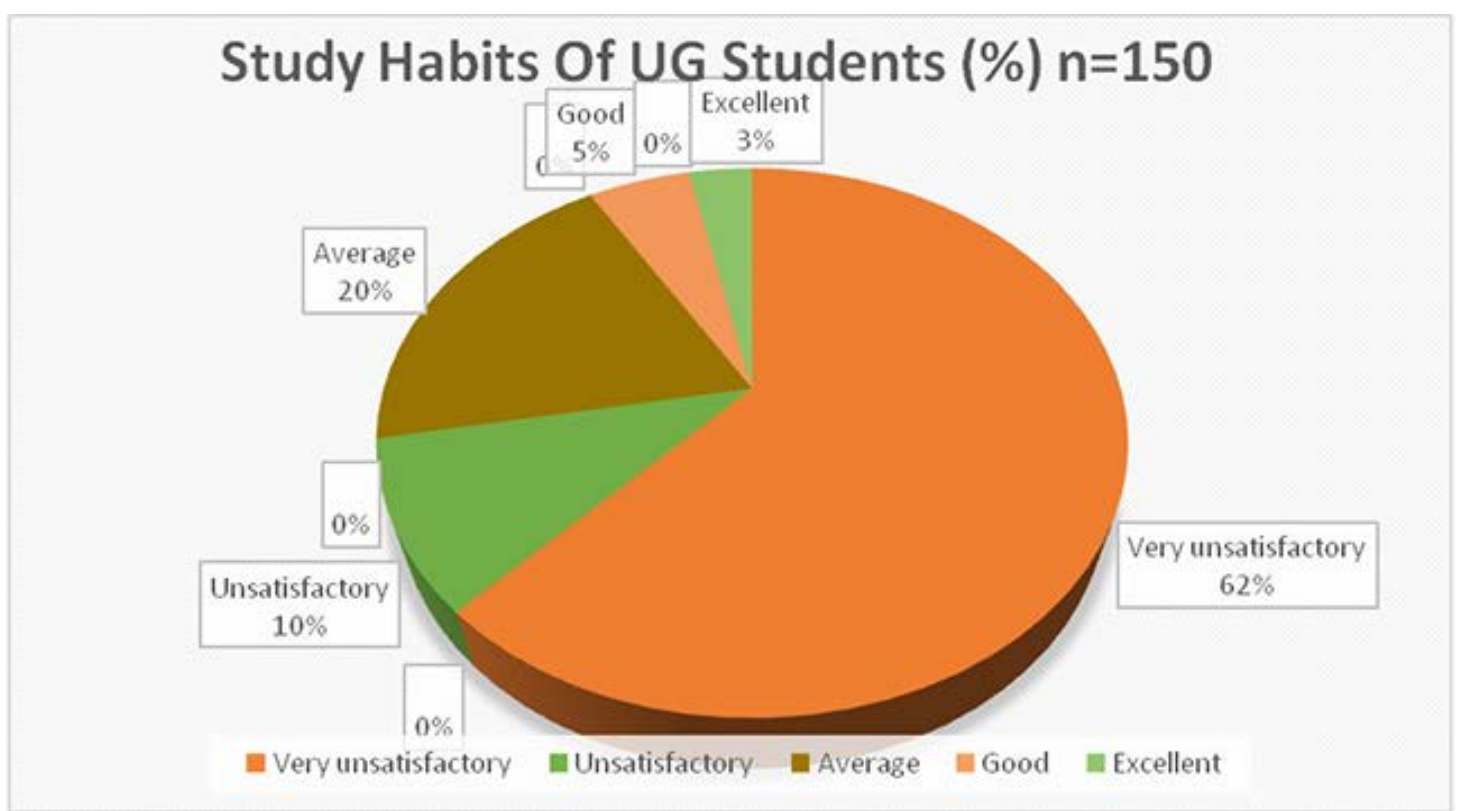

Fig. 1 Study habits of undergraduate students.

Table 2 Difference between study habits of nursing, pharmacy, and physiotherapy undergraduate students $(n=150)$

\begin{tabular}{|l|l|l|l|l|l|l|}
\hline Variable & Course type & $N$ & Mean & Standard deviation & Welch $(H)$ & $p$-Value \\
\hline Study habits & Nursing & 50 & 55.24 & 1.030 & 4.706 & \\
\cline { 2 - 5 } & Physiotherapy & 50 & 49.96 & 1.379 & & \\
\cline { 2 - 5 } & Pharmacy & 50 & 52.92 & 1.358 & & \\
\hline
\end{tabular}

Note: The mean difference is significant at the 0.05 level.

Table 3 Levels of academic stress among health science university students $(n=150)$

\begin{tabular}{|l|l|l|}
\hline Academic stress & Frequency & Percent \\
\hline No stress & 0 & 0 \\
\hline Mild stress & 96 & 64.000 \\
\hline Moderate stress & 54 & 36.000 \\
\hline
\end{tabular}

study conducted by Kumar on undergraduate students shown similar results. ${ }^{11}$ In contrast, the study conducted by Jafari et al showed a mean score of study habits among medical science students were $45.7 \pm 11.36$ out of 90 , where $10 \%$ of them were at a desirable level, $81.3 \%$ on a moderate level, and $8.7 \%$ were on an undesirable level of study habits. Also, nursing and pharmacy students' mean study habit score was 48.66 and 43.33, respectively. ${ }^{15}$ One more study by Looyeh et al showed that the mean score of study habits of medical science students, $48.35 \pm 10.37$, was considered as average level of study habits. ${ }^{12}$ The dissimilarity in the findings may be due to the difference in the classification of study habit scores and the study's geographical area. Also, a self-reported tool used in the study might have caused respondent bias.

In the present study, the prevalence of academic stress among undergraduate students was $100 \%$ and no one in the category of no stress and severe stress. The stress level ranged from mild to moderate, with a mean score of $75.353 \pm 16.463$. Also, physiotherapy students had higher mean stress $(79.220 \pm 17.284)$ compared to nursing (76.880 \pm 13.072$)$ and pharmacy (69.960 \pm 17.528 ) students. Furthermore, there was a statistically significant difference in mean stress scores found between physiotherapy and pharmacy students $(p=0.013)$. The study results were consistent with the study conducted by Gupta et al revealed that the prevalence of the stress among medical students was $91 \% .{ }^{16}$ A study conducted by Opoku-Acheampong et al also showed that $93.3 \%$ of pharmacy students revealed that pharmacy education was stressful. ${ }^{6}$ Furthermore, this study result was consistent with the study conducted by Admi et al also showed that nursing students overall mean stress was mild to moderate. ${ }^{17}$ Also, a study conducted by Sabih et al also showed that $88 \%$ of the physiotherapy students showed mild to severe level of stress, which is consistent with our result. ${ }^{9}$ In contrast, a study conducted by Nerdrum et al showed that nursing students had more distresses compared to physiotherapy and occupational therapy students. ${ }^{7}$ Besides, a study conducted by Sharifirad et al showed pharmacy students prevalence of stress was higher (70.6\%) in comparison with medicine (66.1\%) and dentistry (62.5\%) students. ${ }^{18}$

In the present study, there was no significant relationship found between study habits and academic performance. In addition, there was a significant association found between gender and study habits. This result is consistent with the studies conducted by Looyeh et al and Khan which showed gender has a significant impact on the study habits. ${ }^{12,19}$

There are many limitations to the study. Large sample size could have given a different result. Also, the present study was limited to only undergraduate second-year nursing, pharmacy, and physiotherapy students. Future research can be conducted by including all the branches of medical 
Table 4 Difference in academic stress of nursing, pharmacy, and physiotherapy students $(n=150)$

\begin{tabular}{|l|l|l|l|l|l|l|}
\hline Variable & Course Type & $n$ & Mean & $\begin{array}{l}\text { Standard } \\
\text { deviation }\end{array}$ & F & -Value \\
\cline { 1 - 5 } Academic stress & Nursing & 50 & 76.88 & 1.849 & 4.477 & \\
\cline { 2 - 5 } & Physiotherapy & 50 & 79.22 & 2.444 & \\
\cline { 2 - 5 } & Pharmacy & 50 & 69.96 & 2.479 & & \\
\hline
\end{tabular}

Note: The mean difference is significant at the 0.05 level.

Table 5 Pearson's correlations between study habits and academic stress $(n=150)$

\begin{tabular}{|l|l|l|}
\hline $\begin{array}{l}\text { Study habit-academic } \\
\text { stress }\end{array}$ & Pearson's $\boldsymbol{r}$ & $\boldsymbol{p}$-Value \\
\cline { 2 - 3 } & -0.048 & 0.557 \\
\hline
\end{tabular}

Note: The mean difference is significant at the 0.05 level.

and paramedical courses. Also, further study can be done to explore the cause of stress among undergraduate students.

\section{Conclusion}

In general, the present study result showed study habits of the health science university students are not satisfactory. Besides, they had a mild to moderate level of stress. So, it is essential to identify the means and measures to improve study habits and alleviate the stress of undergraduate students. Poor study habits and academic stress may harm the academic success of the students. In this regard, teachers need to take the necessary steps to correct the study habits of the students, as these skills are learnable. As students of health professionals have a compact curriculum which may be the reason, they may not get adequate time for relaxation. So it is very important to bring changes in their academic routine. Including yoga and meditation in their curriculum may help them relax, and life skill training programs may help them to balance their academic and personal life.

\section{Funding}

The authors thank the Nitte (deemed to be University) for funding this project.

\section{Conflict of Interest}

None declared.

\section{Acknowledgments}

The authors would like to acknowledge the assistance of Ms. Tenzin, Ms. Soumya Shaji, Ms. Selca Saji, Ms. Riya Reji, Ms. Josnamol Joseph, and Mr. Christo Shelly, undergraduate nursing students, Nitte Usha Institute of Nursing Sciences, in data collection process.

\section{References}

1 Yumba W. Academic stress : a case of the undergraduate students [Internet] [Dissertation]. 2010. Available at: http://urn. kb.se/resolve?urn=urn:nbn:se:liu:diva-81902. Accessed May 19, 2021

2 Hj Ramli NH, Alavi M, Mehrinezhad SA, Ahmadi A. Academic stress and self-regulation among university students in
Malaysia: mediator role of mindfulness. Behav Sci (Basel) 2018;8(1):12

3 Fallahchai R. Effectiveness of Academic and Life Skills Instruction on the Freshmen Academic Achievement. 2012

4 Al-Shawwa L, Abulaban AB, Algethami A, Baghlaf S, Abushanab J, Merdad A, Abulaban A. Differences in studying habits between male and female medical students of King Abdulaziz University. Egypt Dent J 2014;60(2):1687-1693

5 Boni RADS, Paiva CE, de Oliveira MA, Lucchetti G, Fregnani JHTG, Paiva BSR. Burnout among medical students during the first years of undergraduate school: prevalence and associated factors. PLoS One 2018; 13(3):e0191746

6 Opoku-Acheampong A, Kretchy IA, Acheampong F, et al. Perceived stress and quality of life of pharmacy students in University of Ghana1. BMC Res Notes 2017;10(1):115

7 Nerdrum P, Rustøen T, Rønnestad MH. Psychological distress among nursing, physiotherapy and occupational therapy students: a longitudinal and predictive study. Scand J Educ Res 2009;53(4):363-378

8 Pandey RA. Self-esteem and academic stress among nursing students. . https://www.nepjol.info/index.php/KUMJ/article/ view/16827. Published 2015. Accessed May 22, 2020

9 Sabih F, Naveed Babur M. Differences in studying habits between male and female students. https://www.researchgate.net/publication/255692264. Published 2013. Accessed May 23, 2020

10 Lee PT. View of Asian students' perceptions of their own study habits. https://so01.tci-thaijo.org/index.php/hbds/article/ view/171667/123275. Published 2010. Accessed March 5, 2021

11 Kumar S. Study habits of undergraduate students. http://www. ripublication.com. Published 2015. Accessed May 21, 2020

12 Rezaie Looyeh H, Seyed Fazelpour SF, Reza Masoule S, Chehrzad MM, Kazem Nejad Leili E. The relationship between the study habits and the academic performance of medical sciences students. J Holist Nurs Midwifery 2017;27(2):65-73

13 Mohamed Arip MAS, Kamaruzaman DN, Roslan A, Ahmad A, Abd Rahman MR. Development, validity and reliability of student stress inventory (SSI) Soc Sci 2015;10(7):1631-1638

14 Mendezabal MJN. Study habits and attitudes: the road to academic success. http://www.open-science-repository.com/ study-habits-and-attitudes-the-road-to-academic-success. html. Published 2013. Accessed May 20, 2020

15 Jafari H. Abbas Aghaei AK. Relationship between study habits and academic achievement in students of medical sciences in Kermanshah-Iran. Adv Med Educ Pract 2019;10:841-842

16 Gupta S, Choudhury S, Das M, Mondol A, Pradhan R. Factors causing stress among students of a medical college in Kolkata, India. Educ Health (Abingdon) 2015;28(1):92

17 Admi H, Moshe-Eilon Y, Sharon D, Mann M. Nursing students' stress and satisfaction in clinical practice along different stages: a cross-sectional study. Nurse Educ Today 2018;68:86-92

18 Sharifirad G, Marjani A, Abdolrahman C, Mostafa Q Hossein S. Stress among Isfahan medical sciences students. J Res Med Sci 2012;17(4):402-406

19 Khan ZN. Factors effecting on study habits. World J Educ Res 2016;3(1):145-150 